\title{
Carbon dioxide versus air insufflation enteroscopy: a systematic review and meta-analysis based on randomized controlled trials
}

\section{다(1) $(9)$}

\author{
Authors \\ Julio Cesar Martins Aquino ${ }^{1}$, Wanderley Marques Bernardo², Diogo Turiani Hourneaux de Moura', Flávio Hiroshi \\ Ananias Morita ${ }^{1}$, Rodrigo Silva de Paula Rocha ${ }^{1}$, Maurício Kazuyoshi Minata ${ }^{1}$, Martin Coronel ${ }^{1}$, Gustavo Luís da Silva \\ Rodela', Robson Kiyoshi Ishida', Rogério Kuga' ${ }^{1}$ Eduardo Guimarães Hourneaux de Moura'
}

Institutions

1 Gastrointestinal Endoscopy Unit of Hospital das Clínicas of São Paulo University, São Paulo 05403-000, São

Paulo, Brazil.

2 Department of Surgery of Hospital das Clínicas of São Paulo University, São Paulo 05403-000, São Paulo, Brazil

submitted 16.8.2017

accepted after revision 8.1.2018

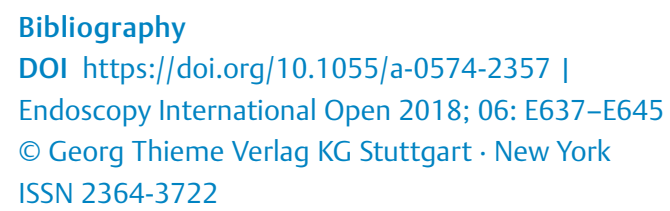

Corresponding author

Martin Coronel, MD, Gastrointestinal Endoscopy Unit of Hospital das Clínicas of São Paulo University, São Paulo 05403-000, São Paulo, Brazil

Fax: +55 11 96061-0205, +55112661-6467

martincoronel0@gmail.com

\section{ABSTRACT}

Objectives To compare the insufflation of $\mathrm{CO}_{2}$ and ambient air in enteroscopy.

Search sources The investigators researched the electronic databases MedLine, Cochrane Library, Central, LILACS, BVS, Scopus and Cinahl. The grey search was conducted in the base of theses of the University of São Paulo, books of digestive endoscopy and references of selected articles and in previous systematic revisions.
Study eligibility criteria The evaluation of eligibility was performed independently, in a non-blind manner, by two reviewers, firstly by title and abstract, followed by complete text. Disagreements between the reviewers were resolved by consensus.

Data collection and analysis method Through the spreadsheet of data extraction, where one author extracted the data and a second author checked the extraction. Disagreements were resolved by debate between the two reviewers. The quality analysis of the studies was performed using the Jadad score. The software RevMan 5 version 5.3 was used for the meta-analysis.

Results Four randomized clinical trials were identified, totaling 473 patients submitted to enteroscopy and comparing insufflation of $\mathrm{CO}_{2}$ and ambient air. There was no statistical difference in the intubation depth between the two groups. When $\mathrm{CO}_{2}$ insufflation was reduced, there was a significant difference in pain levels 1 hour after the procedure (95\% IC, $\left.-2.49[-4.72,-0.26], P: 0.03, \mathrm{I}^{2}: 20 \%\right)$ and 3 hours after the procedure (95\% IC, -3.05 [-5.92, -0.18], $P$ : $\left.0.04, \mathrm{I}^{2}: 0 \%\right)$. There was a usage of lower propofol dosage in the $\mathrm{CO}_{2}$ insufflation group, with significant difference (95\% IC, -67.68 [-115.53, -19.84], P: 0.006, I'2: 0\%). There was no significant difference between the groups in relation to the use of pethidine and to the oxygen saturation.

Limitations Restricted number of randomized clinical trials and nonuniformity of data were limitations to the analysis of the outcomes.

Conclusion The use of $\mathrm{CO}_{2}$ as insufflation gas in enteroscopy reduces the pain levels 1 hour and 3 hours after the procedure, in addition to the reduction of the sedation (propofol) dosage used.

\section{Introduction}

The diagnosis of small intestine diseases has been a challenge for a long time [1]. However, with the development of new diagnostic tools, the evaluation and treatment of these condi- tions has become feasible $[1,2]$. In this context, the carbon dioxide $\left(\mathrm{CO}_{2}\right)$ is the gas of choice for laparoscopic procedures because it is an inert gas, nonflammable, and highly diffusible. It also has rapid absorption and elimination, with minimal cardiopulmonary and acid-base effects on the organism. 
In this sense, one can note the increasing use in endoscopic procedures with diagnostic or therapeutic purposes in upper endoscopy, colonoscopy, endoscopic retrograde cholagiopancreatography (ERCP), and enteroscopy $[3,4]$. For enteroscopy procedures, where the execution time is longer and the volume of insufflated gas is high, the use of $\mathrm{CO}_{2}$ is suggested based on advantages as larger intubation depth, lower abdominal distension and pain, generating more comfort to the patient, and lower dosage of sedatives when compared to the conventional use of ambient air to the insufflation of the intestinal lumen.

Therefore, the small intestine can be adequately evaluated by enteroscopy regardless of the used technique (single balloon or double balloon), using $\mathrm{CO}_{2}$ as the insufflation gas.

It is worth mentioning that many studies have already compared the use of ambient air and $\mathrm{CO}_{2}$ in the various endoscopic procedures, and recently 2 systematic reviews with meta-analysis $[5,6]$ have shown outcomes that have been analyzed in subgroups and that were not previously analyzed. On this premise, this systematic revision is conducted to substantiate the comparison of the use of $\mathrm{CO}_{2}$ in relation to conventional air using the information available in the literature from randomized clinical trials (RCTs) already performed.

\section{Materials and methods}

RCTs were selected that compare the insufflation of $\mathrm{CO}_{2}$ in relation to ambient air in diagnostic enteroscopy. Only complete articles were included. There was no restriction of language or publication date. The systematic revision followed the recommendations of PRISMA (Preferred Reporting Items for Systematic Reviews and Meta-Analyses) [7].

The analysis considered the intubation depth as a primary outcome followed by the secondary outcomes: pain after procedure, sedation dosage, and oxygen saturation.

The search sources researched in the electronic databases were Medline, Cochrane Library, LILACS, BVS, Scopus, and Cinahl. The gray search was performed in the base of theses of the University of São Paulo, chapters of digestive endoscopy books, references of selected articles, and previous systematic revisions.

The search strategy used in Medline included the following terms: "Carbon dioxide $\mathrm{CO}_{2}$," "insufflation," "air," "enteroscopy." The same strategy was used for the other databases according to each search system.

Two authors (Aquino JC and Bernardo WM) conducted the selection of the adequate RCTs initially based on the title and abstract. The complete text was consulted before the inclusion in case of doubts. If the doubt still persisted, a third author was consulted to reach consensus.

The extraction of the data of the selected clinical trials was conducted in an independent manner by 2 authors in spreadsheets, and consensus was reached for all data in case of divergence. Only published data were considered.

Regarding the data analysis, the authors selected the general intubation depth, anterograde intubation depth, retrograde intubation depth, pain after 1 hour and 3 hours, sedative dosage, and peripheral oxygen saturation after the procedure.
The statistical calculations were performed using the software OpenEpi and RevMan version 5.3, and the statistical methods of this study were reviewed before the submission by Bernardo WM from Hospital das Clínicas of São Paulo University.

The bias risk of individual study was considered in the preparation of the present study. The randomization method was not described in other study [8]. Other randomized studies [8, 9] do not describe how the allocation of patients was conducted. Considering the blinding, 1 study [8] does not clearly describe how the double-blinding was done. All the selected studies described clearly the losses or their absence, but 1 study [8] did not use the analysis of the intention to treat of the data obtained.

The analysis measures of the obtained data were all continuous variables using means and standard deviation when available or from the confidence interval with Hook's test $[10,11]$, using the model of fixed effect and inverse variance. Only the intention to treat was considered, and the $95 \%$ confidence interval $(\mathrm{Cl})$ was calculated. A $P$-value $<0.05$ was considered statistically significant.

To synthesize the results, analytical graphs were generated using funnel plot and forest plot. The heterogeneity was calculated using the chi-square test and quantified by the method $\mathrm{I}^{2}$ of Higgins [12]. The sensitivity analysis was performed when values above $50 \%$ of heterogeneity were found.

\section{Results}

\section{Selection of studies}

The search found 288 articles in Medline and 98 articles in other databases. At the end of the selection, 4 RCTs were included in the systematic revision. The search flowchart is presented in - Fig. 1.

\section{Characteristics of studies}

All 4 selected articles are RCTs, published between 2007 and 2014 and in English, although the search was not restricted to language. Two studies were multicenter $[8,9]$.

\section{Participants}

Of the 473 patients submitted to diagnostic enteroscopy, 116 of them were submitted to double-balloon enteroscopy (DBE) $[8,13]$ and 356 of them to single-balloon enteroscopy (SBE) $[9,14]$. All had similar following times for the analyzed outcomes, whereas only 1 RCT [14] did not present pain following 24 hours after enteroscopy.

\section{Intervention}

The intervention group was submitted to enteroscopy with insufflation of $\mathrm{CO}_{2}$, and the control group used ambient air as the insufflation gas. The characteristics of the study are listed in - Table 1.

\section{Outcomes}

The compared outcomes were general intubation depth $[9,13$, $14]$, anterograde intubation depth $[9,14]$, retrograde intubation depth $[9,14]$, pain 1 hour after the procedure $[8,9,14]$, 

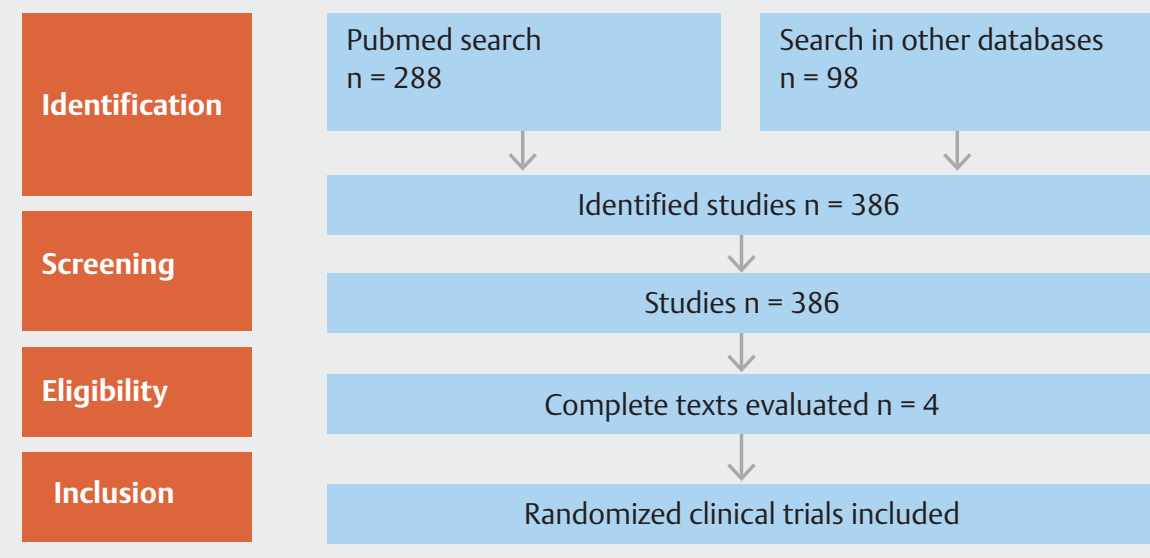

Studies excluded $\mathbf{n}=\mathbf{3 8 2}$

- Unrelated to the theme: 273

- Duplicated: 85

- EC not R: 7

- Case reports: 6

- Abstracts: 5

- Retrospective: 4

- Systematic review: 1

- Studies in animals: 1

- Fig. 1 Literature search flow chart.

- Table 1 Characteristics of the included studies.

\begin{tabular}{|l|l|l|l|l|l|}
\hline Study & Country & Centers (n) & Population (n) & $\begin{array}{l}\text { Intervention (n) CO } \\
\text { enteroscopy }\end{array}$ & $\begin{array}{l}\text { Comparison (n) air } \\
\text { enteroscopy }\end{array}$ \\
\hline Domagk, 2007 & Germany/Norway & 2 & 112 & $54(\mathrm{DBE})$ & $58(\mathrm{DBE})$ \\
\hline Hirai, 2011 & Japan & 1 & 40 & $20(\mathrm{DBE})$ & $20(\mathrm{DBE})$ \\
\hline Lenz, 2014 & Germany/Italy & 4 & 107 & $52(\mathrm{SBE})$ & $55(\mathrm{SBE})$ \\
\hline Li, 2014 & China & 1 & 214 & $106(\mathrm{SBE})$ & $108(\mathrm{SBE})$ \\
\hline
\end{tabular}

anterograde propofol sedation dosage $[8,9]$, anterograde pethidine sedation dosage $[8,14]$, pre-procedure oxygen saturation $\left(\mathrm{SaO}_{2}\right)[13,14]$, and post-procedure oxygen saturation $[13,14]$. Other outcomes such as abdominal distention, procedure time, and abdominal circumference were not included in the analysis because they were measured with different scales, preventing the statistical analysis (abdominal distention in 2 RCTs $[13,14]$ ) or were measured in only 1 article (procedure time [9] and abdominal circumference [14]).

\section{Risk of study bias}

There is no description of the method used for patient randomization in 1 RCT [13], while the randomization was described in 3 RCTs $[8,9,14]$; however, the allocation was not clearly informed in 2 RCTs $[8,9]$. Regarding the blinding, all RCTs were double blind, and only 1 RCT [8] does not provide the description of the blinding. There were losses after the randomization of patients in the same RCT [8], and for the construction of the present systematic revision, only the intention-to-treat analysis was used. Another point of possible bias is the intubation technique of the studies. DBE was used by 2 RCTs $[8,13]$, while the single-balloon enteroscopy was used by another 2 RCTs $[9,14]$. The risk of bias was evaluated through the Jadad score [15], which is a quality evaluation tool for RCTs. All selected studies received 3 points, which was the limit of adequacy for inclusion in the systematic revision ( $\triangleright$ Fig. 2 ).

\section{Results of individual studies}

All 4 RCTs totaled 442 patients included for meta-analysis. All patients were submitted to diagnostic enteroscopy. For the intubation depth, data of 1 RCT [8] were not included because of the absence of the standard deviation of the data provided. Data about pain can be extracted from all trials, but in one of them [13] does not provide the mean and standard deviation. For the other outcomes, the data were grouped and analyzed according to the availability of them in each study, such as anterograde sedation dosage of propofol and pethidine and post-procedure oxygen saturation.

\section{Result synthesis}

All results were quantitative, and not all studies were included for each outcome due to the absence of important data for the analysis.

\section{Primary outcome}

The meta-analysis evaluated using a fixed effect model determined that the general intubation depth was greater in the $\mathrm{CO}_{2}$ insuffulation group, but the results showed high heterogeneity. Employing the random effect and matching the weights of each study, one can note that there was no significant difference between the groups (95\% IC, 48.52 [-37.64, 134.69], $P=$ $0.27, \mathrm{I}^{2}: 87 \%$ ) ( Fig. 3 ). The high heterogeneity found in the meta-analysis was considered real because no outlier study 


\begin{tabular}{c|c|c|c|c|c}
\hline Study & Randomization & Allocation & Blinding & Losses & Jadad score \\
\hline Domagk, 2007 & $\begin{array}{c}\text { Randomization in block } \\
\text { (block of 6 patients) }\end{array}$ & Undescribed & $\begin{array}{c}\text { Double-blind } \\
\text { without description }\end{array}$ & $\begin{array}{c}\text { Double-blind } \\
\text { without description }\end{array}$ & 3 \\
\hline Hirai, 2011 & $\begin{array}{c}\text { Randomized in } \mathrm{CO}_{2} \text { or air } \\
\text { groups }\end{array}$ & Sealed envelopes & Double-blind & 0 & 3 \\
\hline Lenz, 2014 & $\begin{array}{c}\text { Randomization in block } \\
\text { by software }\end{array}$ & Undescribed & Double-blind & 0 & 3 \\
\hline Li, 2014 & $\begin{array}{c}\text { Randomization in block } \\
\text { by software }\end{array}$ & Sealed envelopes & Double-blind & 0 & 5 \\
\hline
\end{tabular}

Fig. 2 Methodological quality analysis - Jadad scale.

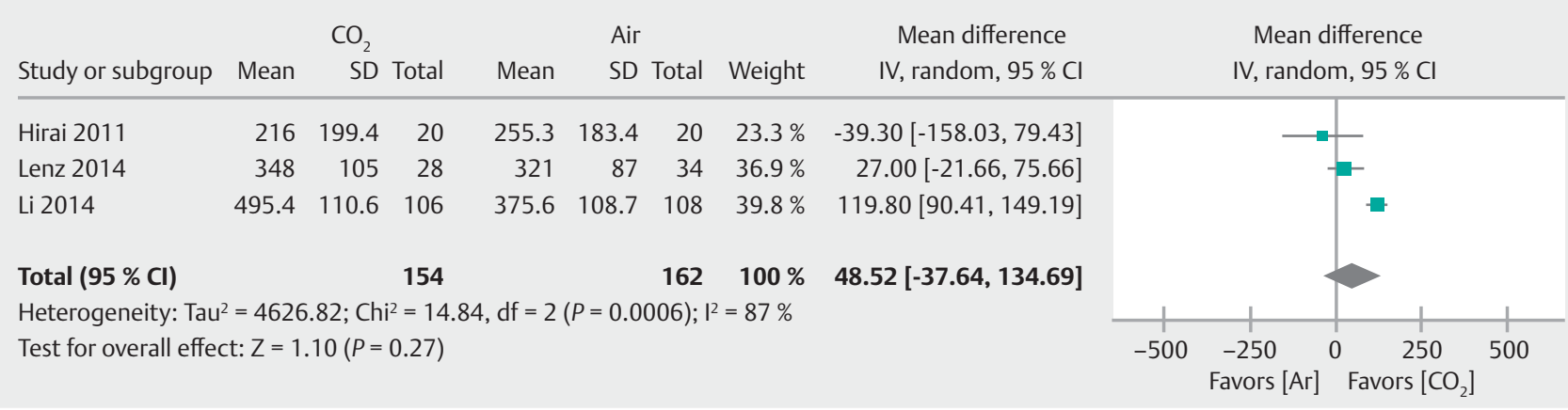

Fig. 3 General intubation depth - random effect.

\begin{tabular}{|c|c|c|c|c|c|c|c|c|c|}
\hline Study or subgroup & Mean & $\begin{array}{r}\mathrm{CO}_{2} \\
\mathrm{SD}\end{array}$ & Total & Mean & $\begin{array}{l}\text { Air } \\
\text { SD }\end{array}$ & Total & Weight & $\begin{array}{c}\text { Mean difference } \\
\text { IV, random, } 95 \% \mathrm{Cl}\end{array}$ & $\begin{array}{c}\text { Mean difference } \\
\text { IV, random, } 95 \% \mathrm{Cl}\end{array}$ \\
\hline Lenz 2014 & 348 & 105 & 28 & 321 & 87 & 34 & $47.7 \%$ & $27.00[-21.66,75.66]$ & $t-$ \\
\hline Li 2014 & 495.4 & 110.6 & 106 & 375.6 & 108.7 & 108 & $52.3 \%$ & $119.80[90.41,149.19]$ & $\rightarrow$ \\
\hline Total (95 \% Cl) & & & 134 & & & 142 & $100 \%$ & $75.51[-15.34,166.36]$ & \\
\hline \multicolumn{9}{|c|}{$\begin{array}{l}\text { Heterogeneity: } \text { Tau }^{2}=3885.33 ; \mathrm{Chi}^{2}=10.24, \mathrm{df}=1(P=0.0001) ; \mathrm{I}^{2}=90 \% \\
\text { Test for overall effect: } Z=1.63(P=0.10)\end{array}$} & $\begin{array}{llll}-200-100 & 0 & 100 & 200 \\
\text { Favors }[\mathrm{Ar}] & \text { Favors }\left[\mathrm{CO}_{2}\right.\end{array}$ \\
\hline
\end{tabular}

Fig. 4 Intubation depth using SBE - random effect.

was identified, and then the random effect analysis was used after the sensitivity analysis.

Analyzing the subgroup that employed the single-balloon enteroscopy (SBE), there was no significant difference in the intubation depth between the groups that used $\mathrm{CO}_{2}$ or ambient air $\left(95 \% \mathrm{IC}, 75.51[-15.34,166.36], p=0.10, \mathrm{I}^{2}: 90 \%\right)$, as shown in $>$ Fig. 4.

For the subgroup that employed DBE, only 1 RCT [9] provides sufficient data for the meta-analysis, considering the intubation depth outcome, and it also does not show a significant difference between the groups (95\% IC, $27.00[-21.66,75.66]$, $P=0.28, I^{2}$ : not applicable). $>$ Fig. 5 illustrates the analysis.

The anterograde $(95 \% \mathrm{IC}, 51.56[-16.53,119.65], P=0.14$, $\left.I^{2}: 94 \%\right)$ and retrograde $(95 \% \mathrm{IC}, 31.88[-77.48,141.23], P=$ $\left.0.57,1^{2}: 97 \%\right)$ intubation depths were larger in the $\mathrm{CO}_{2}$ insufflation group in relation to the ambient air insufflation, but without statistical difference, using the random model in both analyses. The forest plots are found in $\nabla$ Fig. $\mathbf{6}$ and $\triangleright$ Fig.7.

\section{Secondary outcomes}

The pain outcome was evaluated through the visual scale for pain in all clinical trials, but one of the studies [13] only provided quantitative data, which was not included in this meta-analysis. Therefore, the possible meta-analysis outcomes were pain 1 hour, 3 hours, 6 hours after enteroscopy. $\mathrm{CO}_{2}$ insufflation was favorable to a lower presence of pain 1 hour after enteroscopy when compared to the insufflation of ambient air ( $95 \% \mathrm{IC}$, 


\begin{tabular}{|c|c|c|c|c|c|c|c|c|c|}
\hline Study or subgroup & Mean & $\begin{array}{l}\mathrm{CO}_{2} \\
\mathrm{SD}\end{array}$ & Total & Mean & $\begin{array}{l}\text { Air } \\
\text { SD }\end{array}$ & Total & Weight & $\begin{array}{c}\text { Mean difference } \\
\text { IV, random, } 95 \% \mathrm{Cl}\end{array}$ & $\begin{array}{l}\text { Mean difference } \\
\text { IV, fixed, } 95 \% \mathrm{Cl}\end{array}$ \\
\hline Lenz 2014 & 348 & 105 & 28 & 321 & 87 & 34 & $100 \%$ & $27.00[-21.66,75.66]$ & -1 \\
\hline Total (95\% Cl) & & & 28 & & & 34 & $100 \%$ & $27.00[-21.66,75.66]$ & \\
\hline \multicolumn{9}{|c|}{ Test for overall effect: $Z=1.09(P=0.28)$} & 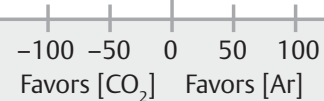 \\
\hline
\end{tabular}

- Fig. 5 Intubation depth using DBE.

\begin{tabular}{|c|c|c|c|c|c|c|c|c|c|c|c|c|}
\hline \multirow{2}{*}{$\begin{array}{l}\text { Study or subgroup } \\
\text { Lenz } 2014\end{array}$} & \multirow{2}{*}{$\begin{array}{r}\text { Mean } \\
254\end{array}$} & \multicolumn{2}{|c|}{$\begin{array}{l}\mathrm{CO}_{2} \\
\text { SD Total }\end{array}$} & \multirow{2}{*}{$\begin{array}{r}\text { Mean } \\
238\end{array}$} & \multicolumn{2}{|c|}{ Air } & \multirow{2}{*}{$\begin{array}{l}\text { Weight } \\
48.8 \%\end{array}$} & \multirow{2}{*}{$\begin{array}{c}\text { Mean difference } \\
\text { IV, random, } 95 \% \mathrm{Cl} \\
16.00[-11.39,43.39]\end{array}$} & \multicolumn{4}{|c|}{$\begin{array}{c}\text { Mean difference } \\
\text { IV, random, } 95 \% \mathrm{Cl}\end{array}$} \\
\hline & & 80.3 & 48 & & 55.2 & 50 & & & & & $=-$ & \\
\hline Li 2014 & 323.8 & 64.2 & 106 & 238.3 & 68.6 & 108 & $51.2 \%$ & $85.50[67.70,103.30]$ & & & 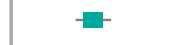 & \\
\hline Total (95 \% Cl) & & & 154 & & & 158 & $100 \%$ & $51.56[-16.53,119.65]$ & & & & \\
\hline $\begin{array}{l}\text { Heterogeneity: Tau } \\
\text { Test for overall effec }\end{array}$ & $\begin{array}{l}=2276 \\
t: Z=1\end{array}$ & $\begin{array}{l}\text { 26; Chi } \\
8(P=\end{array}$ & $\begin{array}{l}\mathrm{i}^{2}=17 \\
0.14)\end{array}$ & $\mathrm{df}=1$ & $<0.0$ & 001); $1^{2}$ & $=94 \%$ & & $\begin{array}{l}\mid \\
-200\end{array}$ & $\begin{array}{l}-100 \\
\text { Favors [Ar] }\end{array}$ & $\begin{array}{lc}0 & 100 \\
\text { Favors }\left[\mathrm{CO}_{2}\right]\end{array}$ & 200 \\
\hline
\end{tabular}

- Fig. 6 Anterograde intubation depth-random effect.

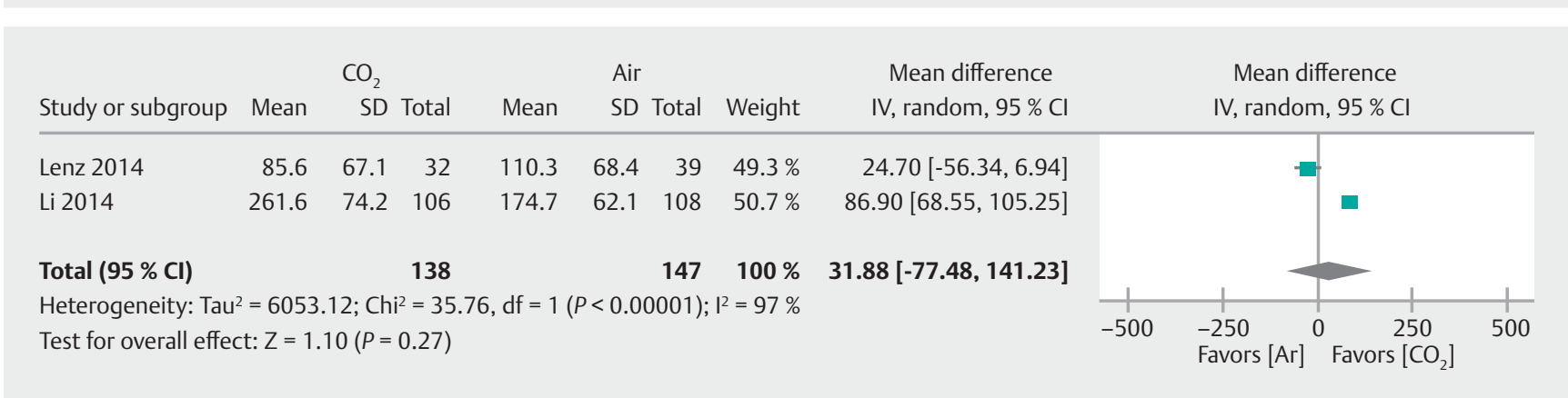

Fig.7 Retrograde intubation depth - random effect.

$\left.-2.49[-4.72,-0.26], P=0.03, \mathrm{I}^{2}: 20 \%\right)$, with low heterogeneity and using the fixed model, as shown in $>$ Fig. 8.

For pain 3 hours and 6 hours after enteroscopy, only 2 RCTs $[8,14]$ provided analyzable data. There was less pain 3 hours after enteroscopy in the group that used $\mathrm{CO}_{2}$, with significant difference (95\% IC, $-3.05[-5.92,-0.18], P=0.04, I^{2}$ : $0 \%$ ). After 6 hours, there was no difference in relation to pain between the groups (95\% IC, $-1.08[-3.24,1.08], P=0.33, I^{2}$ : $\left.0 \%\right)$. The graphs are found in > Fig. $\mathbf{9}$ and $>$ Fig. 10 .

Another analyzed outcome was related to the use of sedation during enteroscopy execution. For the anterograde enteroscopy, the use of propofol was lower in the $\mathrm{CO}_{2}$ insufflation group compared to the air use group, with significant difference (95\% IC, -67.68 [-115.53, -19.84], $P=0.006, \mathrm{I}^{2}$ : $0 \%$ ) and using the fixed model, as illustrated in $>$ Fig. 11.

Considering the use of pethidine, there was no observable difference in its dosage in the anterograde enteroscopy procedures that used $\mathrm{CO}_{2}$ in relation to ambient air (95\% IC, -1.84 $\left.[-7.99,4.31], P=0.56, I^{2}: 51 \%\right)$, using the random effect in the meta-analysis, because the other study [8] had a standard deviation equal to 0 in the used pethidine dosage; thus, the lower decimal standard deviation close to zero was considered ( $\triangleright$ Fig. 12).

The last analyzed outcome was the oxygen saturation after enteroscopy. The meta-analysis has not shown statistical difference between the $\mathrm{CO}_{2}$ and air groups after enteroscopy (95\% IC, $\left.0.25[-0.12,0.61], P=0.18, I^{2}: 0 \%\right)$, using the fixed effect ( Fig.13).

\section{Discussion}

In the context of the main objective, when comparing the use of $\mathrm{CO}_{2}$ as a gas of choice for enteroscopy insufflation in relation to the use of traditional ambient air, the use of $\mathrm{CO}_{2}$ during enteroscopy provides less discomfort after 1 hour and after 3 hours and requires less use of sedation with propofol, but it does not show differences in the depth of intestinal intubation (even when compared to similar enteroscopy techniques) and 


\begin{tabular}{|c|c|c|c|c|c|c|c|c|c|c|c|c|}
\hline Study or subgroup & Mean & $\begin{array}{r}\mathrm{CO}_{2} \\
\mathrm{SD}\end{array}$ & Total & Mean & $\begin{array}{l}\text { Air } \\
\text { SD }\end{array}$ & Total & Weight & $\begin{array}{l}\text { Mean difference } \\
\text { IV, fixed, } 95 \% \mathrm{Cl}\end{array}$ & & \multicolumn{3}{|c|}{$\begin{array}{l}\text { Mean difference } \\
\text { IV, fixed, } 95 \% \mathrm{CI}\end{array}$} \\
\hline Domagk 2007 & 2.8 & 3.6 & 54 & 5.9 & 10.8 & 58 & $57.4 \%$ & $-3.10[-6.04,-0.16]$ & & $\rightarrow$ & & \\
\hline Lenz 2014 & 3.4 & 9.1 & 32 & 8.9 & 17 & 39 & $12.9 \%$ & $-5.5[-11.70,0.70]$ & $\leftarrow$ & & & \\
\hline Li 2014 & 3 & 15.2 & 106 & 3 & 15.3 & 108 & $29.7 \%$ & $0.00[-4.09,4.09]$ & & & & \\
\hline Total $(95 \% \mathrm{Cl})$ & & & 192 & & & 205 & $100 \%$ & $-2.49[-4.72,-0.26]$ & & & & \\
\hline \multicolumn{8}{|c|}{ Test for overall effect: $Z=2.19(P=0.03)$} & & -10 & $\begin{array}{cc}-5 & 0 \\
\text { Favors }\left[\mathrm{CO}_{2}\right]\end{array}$ & $\begin{array}{lr}0 & 5 \\
\text { Favors [Ar] }\end{array}$ & 10 \\
\hline
\end{tabular}

- Fig. 8 Pain 1 hour after enteroscopy-fixed effect.

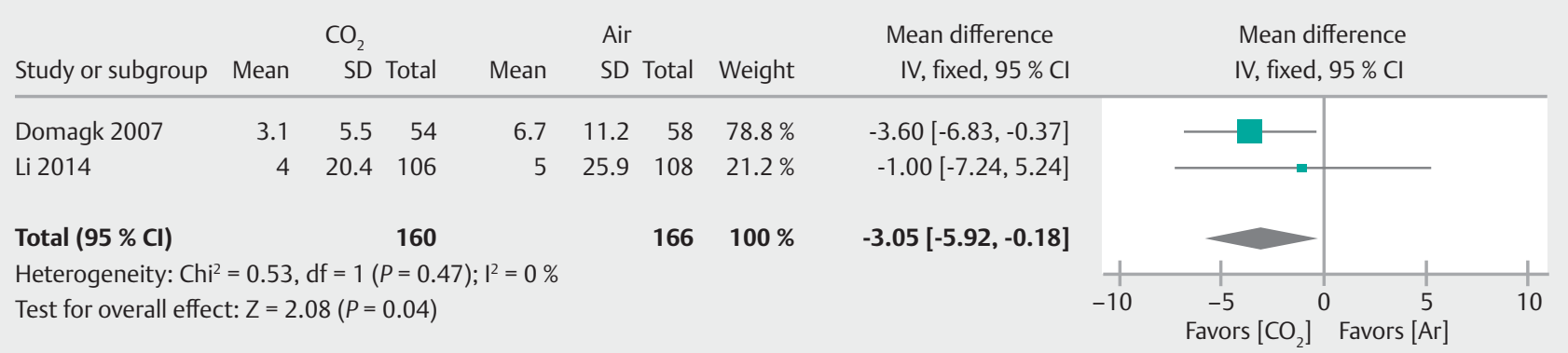

Fig. 9 Pain 3 hours after enteroscopy-fixed effect.

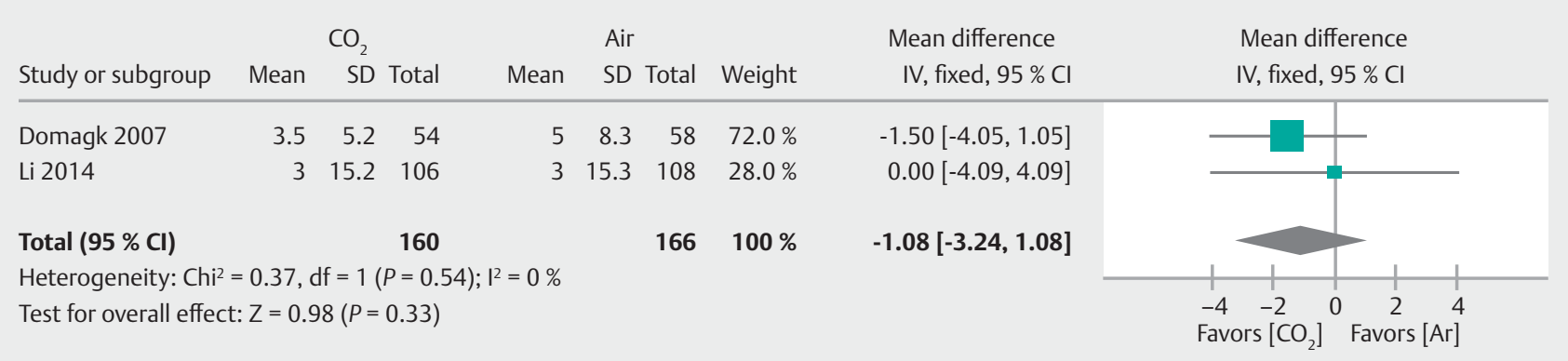

- Fig. 10 Pain 6 hours after enteroscopy - fixed effect.

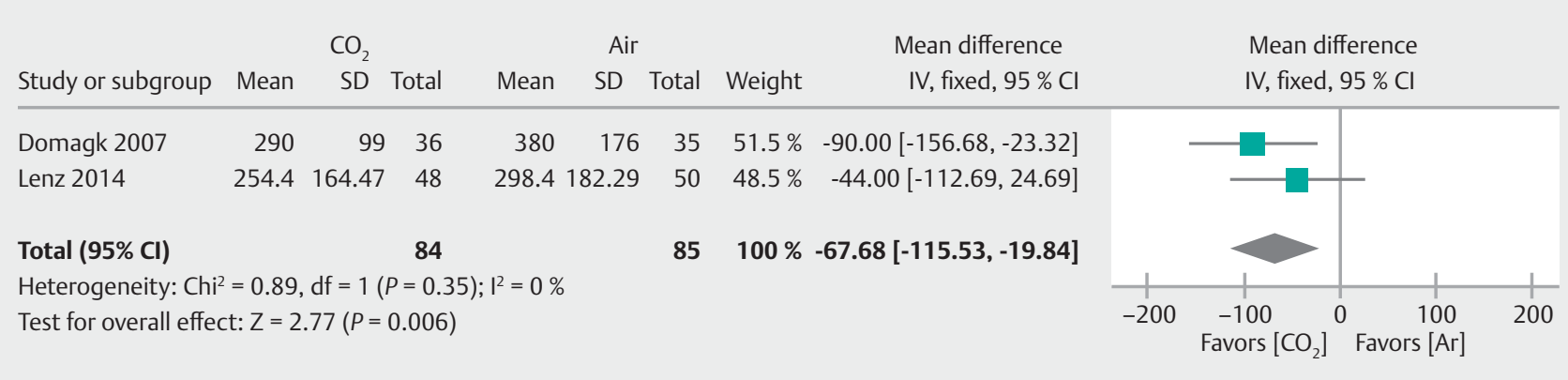

Fig. 11 Anterograde sedation dosage of propofol-fixed effect. 


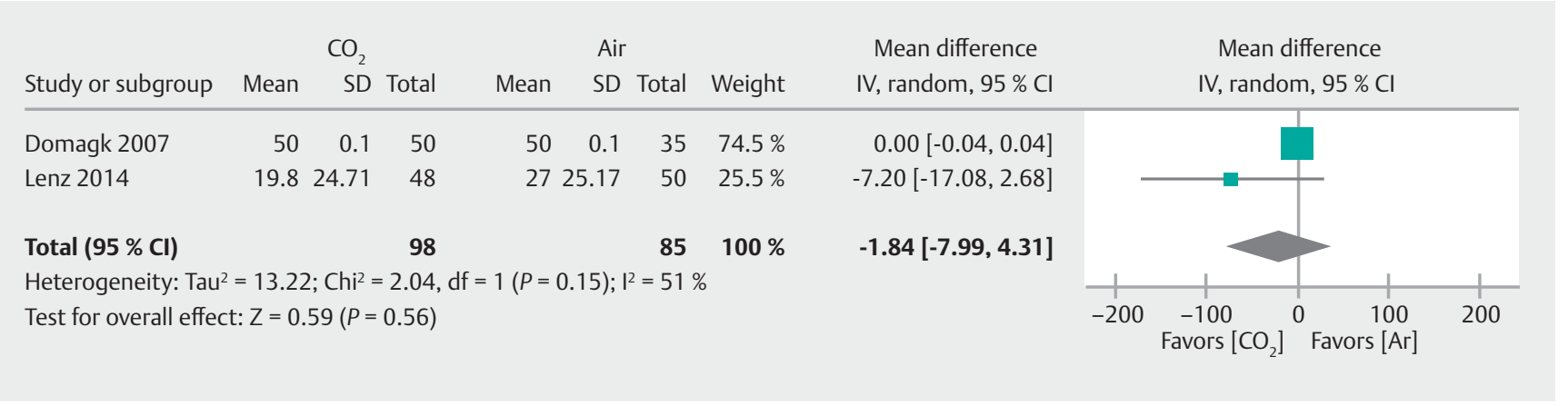

- Fig. 12 Anterograde sedation dosage of pethidine-random effect.

\begin{tabular}{|c|c|c|c|c|c|c|c|c|c|c|c|c|}
\hline Study or subgroup & Mean & $\begin{array}{r}\mathrm{CO}_{2} \\
\mathrm{SD}\end{array}$ & Total & Mean & $\begin{array}{l}\text { Air } \\
\text { SD }\end{array}$ & Total & Weight & $\begin{array}{l}\text { Mean difference } \\
\text { IV, fixed, } 95 \% \mathrm{Cl}\end{array}$ & & $\begin{array}{l}\text { Mean di } \\
\text { IV, fixed, }\end{array}$ & $\begin{array}{l}\text { ifference } \\
\text {, } 95 \% \mathrm{Cl}\end{array}$ & \\
\hline Hirai 2011 & 96.6 & 1.6 & 20 & 96.7 & 1.6 & 20 & $13.3 \%$ & $-0.10[-1.09,-0.89]$ & & 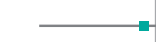 & & \\
\hline Li 2014 & 97.3 & 1.5 & 106 & 97 & 1.4 & 108 & $86.7 \%$ & $0.30[-0.09,0.69]$ & & & - & \\
\hline Total (95 \% Cl) & & & 126 & & & 128 & $100 \%$ & $0.25[-0.12,0.61]$ & & & & \\
\hline \multicolumn{9}{|c|}{ Heterogeneity: $\mathrm{Chi}^{2}=0.54, \mathrm{df}=1(P=0.46) ; \mathrm{I}^{2}=0 \%$} & + & + & 中 & + \\
\hline \multicolumn{9}{|c|}{ Test for overall effect: $Z=1.34(P=0.18)$} & -2 & $\stackrel{-1}{\text { Favors }\left[\mathrm{CO}_{2}\right]}$ & $\begin{array}{lc}0 & 1 \\
& \end{array}$ & 2 \\
\hline
\end{tabular}

- Fig.13 Oxygen saturation after enteroscopy-fixed effect.

in peripheral oxygen saturation indices when compared to the use of ambient air.

For patients submitted to diagnostic enteroscopy, as well as other endoscopic procedures, the use of gas for the distention of the intestinal lumen is necessary, and traditionally ambient air is employed for this purpose; however, the ambient air is not well absorbed by the gastrointestinal tract, and it must be removed to avoid abdominal distention and consequent discomfort and pain $[2,3,16,17]$. Considering also the fact that enteroscopy is a longer procedure (independent of the technique using single balloon or double balloon [1,2]), $\mathrm{CO}_{2}$ as insufflation gas during enteroscopy is a strong prerogative for potential benefits of its use due to its characteristics of rapid absorption and diffusion.

The studies generally showed a low rate of complications related to use of $\mathrm{CO}_{2}$ or air for insufflation during enteroscopy. For this reason, it is probably related to the type of enteroscopic technique, anatomical or surgical alterations in the abdomen and to the type of therapeutic procedure been performed for example: balloon trauma causing bleeding or perforation, segmental enteritis after argon plasma coagulation, intestinal necrosis after epinephrine injection. In procedures via the anterograde approach, pancreatitis is the most common and severe complication [18].

The primary outcome of general intubation depth from this systematic review was greater in the $\mathrm{CO}_{2}$ group with a statistically significant difference, but with high heterogeneity between the trials using a fixed model effect. By utilizing the random model in the meta-analysis, one can note that the hetero- geneity remains high, but the weights of the studies are matched between them in the analysis, being more appropriate from a statistical viewpoint and less prone to false interpretations. Thus, by using the analysis with random effect for the general intubation depth, there is no statistical difference between the use of $\mathrm{CO}_{2}$ and ambient air, even with preference to a larger intubation depth by using $\mathrm{CO}_{2}$.

One important point to be discussed is the pain outcome. The data provided by the clinical trials of the present systematic review allows for comparison for the 1,3 , and 6 hours after the execution of the enteroscopy, although not all trials were included in the comparison of each outcome due to the lack of data provided by them. We found significant difference with lower abdominal pain in the $\mathrm{CO}_{2}$ insufflation group 1 hour and 3 hours after the performance of the enteroscopy, when the patient recovers from the sedation or anesthesia. This finding is significant because lower admoninal discomfort is important for improved recovery and patient satisfaction after the procedure. In clinical practice, patients who can benefit the most from the use of $\mathrm{CO}_{2}$ gas insufflation are those who have cardiovascular comorbidities, since the less pain caused by $\mathrm{CO}_{2}$ would not overload the cardiac vascular system. Other groups with great benefit potential are patients with previous abdominal surgery or documented histories of intra-abdominal adhesions, due to the high rate of $\mathrm{CO}_{2}$ absorption causing less abdominal discomfort. On the other hand, there is still insufficient data on the actual respiratory effects that $\mathrm{CO}_{2}$ can cause in patients with severe chronic obstructive pulmonary disease. 
Regarding the use of sedation, there was statistical difference in relation to the use of lower dosages of propofol for sedation of anterograde enteroscopy, although there was no difference in the use of pethidine, confirming the fact that $\mathrm{CO}_{2}$ causes lower discomfort and pain by requiring a lower propofol dosage during the execution of enteroscopy.

There was no difference in the oxygen saturation levels after the procedure between the $\mathrm{CO}_{2}$ and ambient air groups, and this is an important point that strengthens the security of the use of $\mathrm{CO}_{2}$ for long procedures and causes no negative impacts from the cardiopulmonary and acid-base viewpoints.

It is noteworthy that a systematic review with meta-analysis was performed in 2016 [5], where the depth of intubation, abdominal pain, and $\mathrm{CO}_{2}$ retention were analyzed, not all other outcomes or subgroups that the present review was able to list and analyze.

\section{Limitations}

Some limitations were identified in the present revision. An important initial limiting factor was the small quantity of RCTs available in the literature, with the consequent restricted amount of data. Besides that, there were divergences in the scales used to measure the outcomes (e.g., in 1 RCT [13]), which measured pain using the visual analog scale but grouped the patients in groups of low/moderate and severe pain providing absolute numbers, making impossible the meta-analysis of the data provided.

Important outcomes, such as procedure time, diagnostic yield, blood levels of gases, and abdominal distention were singly evaluated in individual studies and therefore were not subjected to comparison.

\section{Conclusion}

In conclusion, the use of $\mathrm{CO}_{2}$ in enteroscopy provides less abdominal discomfort with less use of sedation using propofol in relation to the insufflation with ambient air. These conclusions are of great importance for routine clinical use of $\mathrm{CO}_{2}$ as the gas of choice for insufflation in enteroscopy diagnostic procedures.

\section{Funding}

This research received no specific grant from any funding agency in the public, commercial, or not-for-profit sectors.

\section{Competing interests}

None

\section{References}

[1] Yamamoto $\mathrm{H}$, Sekine $\mathrm{Y}$, Sato $\mathrm{Y}$ et al. Total enteroscopy with a nonsurgical steerable double-balloon method. Gastrointest Endosc 2001; 53: $216-220$

[2] Tsujikawa T, Saitoh Y, Andoh A et al. Novel single-balloon enteroscopy for diagnosis and treatment of the small intestine: preliminary experiences. Endoscopy 2008; 40: 11-15

[3] Wang WL, Wu ZH, Sun Q et al. Meta-analysis: the use of carbon dioxide insufflation vs. room air insufflation for gastrointestinal endoscopy. Aliment Pharmacol Ther 2012; 35: 1145-1154

[4] Sumanac K, Zealley I, Fox BM et al. Minimizing postcolonoscopy abdominal pain by using $\mathrm{CO}_{2}$ insufflation: a prospective, randomized, double blind, controlled trial evaluating a new commercially available $\mathrm{CO}_{2}$ delivery system. Gastrointest Endosc 2002; 56: 190 - 194

[5] Nishizawa T, Suzuki H, Fujimoto A et al. Effects of carbon dioxide insufflation in balloon-assisted enteroscopy: a systematic review and meta-analysis. United European Gastroenterol J 2016; 4: 11-17

[6] Shiani A, Lipka S, Lai A et al. Carbon dioxide versus room air insufflation during balloon-assisted enteroscopy: a systematic review with meta-analysis. Endosc Int Open 2017; 5: E67-E75

[7] Shamseer L, Moher D, Clarke M et al. Preferred reporting items for systematic review and meta-analysis protocols 2015: elaboration and explanation. BMJ 2015; 350: g7647

[8] Domagk D, Bretthauer M, Lenz P et al. Carbon dioxide insufflation improves intubation depth in double-balloon enteroscopy: a randomized, controlled, double-blind trial. Endoscopy 2007; 39: 1064 1067

[9] Lenz P, Meister T, Manno $\mathrm{M}$ et al. $\mathrm{CO}_{2}$ insufflation during single-balIoon enteroscopy: a multicenter randomized controlled trial. Endoscopy 2014; 46: $53-58$

[10] Hook EB, Regal RR. Accuracy of alternative approaches to capture-recapture estimates of disease frequency: internal validity analysis of data from five sources. Am J Epidemiol 2000; 152: 771 - 779

[11] Hook EB, Regal RR. Recommendations for presentation and evaluation of capture-recapture estimates in epidemiology. J Clin Epidemiol 1999; 52: 917-926

[12] Higgins J, Green SE. Cochrane Handbook for Systematic Reviews of Interventions Version 5.1.0. The Cochrane Collaboration; 2011: Available at www.cochrane-handbook.org

[13] Hirai F, Beppu T, Nishimura T et al. Carbon dioxide insufflation compared with air insufflation in double-balloon enteroscopy: a prospective, randomized, double-blind trial. Gastrointest Endosc 2011; 73: $743-749$

[14] Li X, Zhao Y], Dai J et al. Carbon dioxide insufflation improves the intubation depth and total enteroscopy rate in single-balloon enteroscopy: a randomised, controlled, double-blind trial. Gut 2014; 63: $1560-1565$

[15] Jadad AR, Moore RA, Carroll D et al. Assessing the quality of reports of randomized clinical trials: is blinding necessary? Control Clin Trials 1996; 17: $1-12$

[16] Dellon ES, Hawk JS, Grimm IS et al. The use of carbon dioxide for insufflation during Gl endoscopy: a systematic review. Gastrointest Endosc 2009; 69: 843 - 849

[17] May A, Nachbar L, Wardak A et al. Double-balloon enteroscopy: preliminary experience in patients with obscure gastrointestinal bleeding or chronic abdominal pain. Endoscopy 2003; 35: 985 - 991

[18] Kopacova M, Tacheci I, Rejchrt S et al. Double balloon enteroscopy and acute pancreatitis. World J Gastroenterol 2010; 16: 2331-2340

[19] Church J, Delaney C. Randomized, controlled trial of carbon dioxide insufflation during colonoscopy. Dis Colon Rectum 2003; 46: 322 326 
[20] Bretthauer M, Thiis-Evensen E, Huppertz-Hauss G et al. NORCCAP: a randomized trial to assess the safety and efficacy of carbon dioxide versus air insufflation in colonoscopy. Gut 2002; 50: 604-607

[21] Geyer M, Guller U, Beglinger C. Carbon dioxide insufflation in routine colonoscopy is safe and more comfortable: results of a randomized controlled double-blinded trial. Diagn Ther Endosc 2011; 2011: 378906

[22] Nonaka S, Saito Y, Takisawa $\mathrm{H}$ et al. Safety of carbon dioxide insufflation for upper gastrointestinal tract endoscopic treatment of patients under deep sedation. Surg Endosc 2010; 24: 1638 - 1645 